\title{
Aspectos biofísicos de la transmisión del SARS-CoV-2 y medidas para contrarrestar la COVID-19: una revisión integrativa
}

\section{Biophysics aspects of transmission of SARS-CoV-2 and measures to reduce the COVID-19: a comprehensive review}

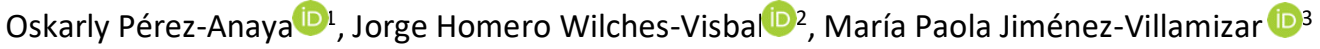

1. Universidad del Magdalena. Santa Marta, Colombia. Correo: operez@unimagdalena.edu.co - https://orcid.org/0000-0002-0701-7847

2. Universidad del Magdalena. Santa Marta, Colombia. Correo: jwilches@unimagdalena.edu.co - http://orcid.org/0000-0003-3649-5079

3. Universidad del Magdalena. Santa Marta, Colombia. Correo: mjimenezv@unimagdalena.edu.co - http://orcid.org/0000-0003-2264-7422

Tipología: Artículo de revisión

Para citar este artículo: Pérez-Anaya O, Wilches-Visbal JH, Jiménez-Villamizar MP. Aspectos biofísicos de la transmisión del SARS-CoV-2 y medidas para contrarrestar la COVID-19: una revisión integral. Duazary. 2021 julio; 18(3): 268- 282. Doi: https://doi.org/10.21676/2389783X.4226

Palabras clave: SARSCoV-2; transmisión; supresión; contención; mitigación; medidas.

\section{Keywords:} SARS-CoV-2; transmission; suppression; containment; mitigation; measures.

\section{RESUMEN}

La pandemia por COVID-19 ha tenido al mundo en vilo desde su inicio en diciembre de 2019 al sur de China. Su alcance global obedece a que el SARS-CoV-2, su agente etiológico, ha mostrado una alta facilidad para transmitirse entre humanos. Desde entonces, Gobiernos de todas las naciones han desplegado una batería de medidas para disminuir sus consecuencias. De acuerdo con el crecimiento del contagio, se emplean medidas de contención, mitigación o supresión. La base científica de las medidas se deriva del conocimiento de las características biológicas del virus y de sus vías de transmisión. Por tanto, en este trabajo se revisarán la biología del coronavirus, la física de su transmisión y el concepto de dosis de infección que permiten comprender las intervenciones sanitarias empleadas para disminuir los casos y fallecimientos por la enfermedad, especialmente en el contexto latinoamericano.

\section{ABSTRACT}

COVID-19 pandemic has had the world on edge since its inception in December 2019 in southern China. Its global reach obeys that SARS-CoV-2, the etiological agent, has shown a high facility to be transmitted between humans. Since then, governments of all nations have deployed a battery of measures to lessen its consequences. According to the growth of the contagion, containment, mitigation, or suppression measures are used. The scientific basis for the measures is derived from knowledge of the biological characteristics of the virus and its transmission routes. Therefore, this work will review the biology of the coronavirus, the physics of its transmission and the concept of infection doses that allow understanding the health interventions used to reduce cases and deaths from the disease, especially in the Latin American context. 


\section{INTRODUCCIÓN}

La enfermedad por coronavirus 2019 (COVID-19), una afección respiratoria de carácter agudo causada por el coronavirus SARS-CoV-2, ha sido responsable de la pandemia todavía en curso ${ }^{1}$. El SARS-CoV-2 se caracteriza por su fácil propagación que, aunada al poco conocimiento sobre tratamientos efectivos y a la falta de vacunas, generó prontamente una alta preocupación en los sistemas de salud y la economía mundial ${ }^{2,3}$.

Los primeros casos fueron reportados en diciembre de 2019 en Wuhan (China), cuando un grupo de personas comenzaron a presentar cuadros sintomáticos relacionados con una infección respiratoria grave ${ }^{4}$. A raíz de la rápida expansión del nuevo coronavirus hacia diferentes continentes, la Organización Mundial de la Salud (OMS) declaró, el 12 de marzo de $2020^{5}$, a la COVID-19 como pandemia.

Como resultado de su rápida propagación, en todo el planeta se empezaron a implementar políticas y medidas para frenar la expansión del virus, a fin de disminuir el contagio y el número de muertos ${ }^{6}$. No obstante, a la fecha, la COVID-19 es responsable de 104,7 millones de casos y alrededor de 2,2 millones de muertos en todo el mundo ${ }^{7}$. Frente a epidemias (o pandemias en el peor escenario), la OMS ha sugerido la aplicación de medidas de prevención, mitigación y supresión ${ }^{8,9}$.

Para la COVID-19 se han contemplado como medidas de prevención el uso de máscaras, el lavado de manos, evitar espacios con poca ventilación, y limpiar y desinfectar superficies. Como medidas de mitigación se sugirió el aislamiento de casos sospechosos en hogares, distanciamiento social sostenido para grupos de riesgo (adultos mayores y personas con comorbilidades) y distanciamiento físico. Finalmente, como medidas de supresión, se llevaron a cabo cuarentenas generalizadas y cierres de barrios o localidades, establecimientos educativos como colegios o universidades, locales comerciales de empresas y almacenes, al igual que lugares de entretenimiento como bares, restaurantes o cines, entre otros ${ }^{10}$. Tales medidas han sido acogidas por casi todos los países del mundo. Sin embargo, como consecuencia de varias de ellas, se ha visto afectado de manera negativa el bienestar general de las personas, es decir, la pandemia ha transformado la escena social ${ }^{11}$.

Los países latinoamericanos no han sido ajenos a la implementación de las recomendaciones sanitarias de la OMS respecto a la pandemia. Con todo, por la rápida transmisibilidad del coronavirus, los problemas estructurales de los sistemas sanitarios, la alta informalidad económica y la poca confianza de los habitantes en sus Gobiernos, fue todo un reto poder implementarlas ${ }^{12}$. Aunque en los países de la región se tomaron medidas parecidas, el hecho de decidir hacerlo en momentos diferentes modificó la evolución de la pandemia entre varios de ellos ${ }^{13}$. Asimismo, los Gobiernos de la región, en cabeza de sus ministerios de Salud, Educación y Ciencia, han propendido a la concreción de diversos productos de tipo tecnológico, junto a las medidas tradicionales de control epidemiológico que parten del conocimiento de la biología del virus y de la física de su transmisión ${ }^{14,15}$.

El propósito de este trabajo de investigación es examinar los aspectos biofísicos más importantes del virus y sus vías de transmisión, así como las principales medidas dirigidas a reducir el contagio por COVID-19 en Latinoamérica, a través de una revisión integrativa.

\section{MATERIALES Y MÉTODOS}

Se llevó a cabo una revisión integrativa que consistió en el análisis de artículos científicos y documentos oficiales de organizaciones multilaterales $y$ gubernamentales, con la intención de establecer conclusiones genéricas en relación con las medidas aplicadas para reducir el contagio de la COVID-19 a partir del conocimiento previo de la biofísica de la transmisión del virus. Para ello, fue necesario plantear las siguientes preguntas: ¿cuáles son los detalles biológicos más relevantes del virus?, ¿cómo es la transmisión del virus y qué principios físicos la explican?, y ¿cuáles fueron las medidas que se 
utilizaron en diversos países para tratar de reducir el contagio por COVID-19?

Para tanto, fue imprescindible realizar una delimitación temporal entre diciembre de 2019 y enero de 2021. Se emplearon palabras clave en español e inglés tales como: "medidas" (en inglés measures), "prevención" (en inglés prevention), "mitigación" (en inglés mitigation) o "supresión" (en inglés suppression), "aerosol", "transmisión" (en inglés transmission), "dosis de infección" (en inglés infection doce or load), "física de fluidos" (en inglés flow physics), "SARS-CoV-2" y "COVID-19", con el apoyo de los operadores booleanos or y and. Para obtener la información se utilizaron las bases de datos Scielo, Lilacs y PubMed.

Para el proceso de selección e inclusión de las investigaciones se revisaron de forma inicial (primera fase) los títulos y resúmenes de los artículos que tenían disponibles al menos estos dos ítems, con la finalidad de que no se presentaran inconvenientes asociados con el acceso a los documentos en caso de su avance a segunda fase, donde se analizaron la metodología empleada y los resultados. Los artículos se escogieron de forma dicotómica (sí o no) y cualitativa, esto es, si había presencia de los criterios relacionados con el estudio o no.

El análisis detallado de los documentos, se efectuó siguiendo la secuencia empleada en el estudio de Aguilar Cordero et $a l^{16}$ :

- Análisis de documentos: permite extraer la información más destacada y diferenciarla según los ítems (título y resumen) más relevantes.

- Síntesis de la información: para hacer posible el ordenamiento y la combinación de la información extraída, de acuerdo con las diferencias y semejanzas encontradas entre las distintas bases de datos.

Se descartaron los reportes y series de casos, así como publicaciones sin proceso de revisión por pares, como suelen ser las editoriales y las cartas al editor. Esto último se ejecutó previo al inicio de la primera fase.

\section{Declaración sobre aspectos éticos}

La presente revisión se enmarca en las normas establecidas en la Declaración de Helsinki de 1975 y demás derivaciones existentes. También se acogió a la Resolución 8430 de 1993 del Ministerio de Salud de Colombia al ser una investigación sin riesgo para los seres humanos. Por último, el hecho de que la información empleada para este estudio sea de fuentes secundarias ya publicadas también lo exime de cualquier violación a las normas o lineamientos antes expuestos.

\section{RESULTADOS Y DISCUSIÓN}

\section{Contextualización de la pandemia}

Desde finales de 2019, el mundo viene enfrentando una emergencia sanitaria nunca antes vista debido a su alcance global, al número de contagiados y fallecidos, y su gran difusión y repercusión mediática ${ }^{17-19}$.

En teoría, la toma oportuna de decisiones permite el control de cualquier epidemia sobre la base de conocer, a fondo, la naturaleza de la enfermedad y el modo de transmisión de su agente etiológico ${ }^{20}$. Sin embargo, debido a la escasa información sobre el nuevo coronavirus y su modo de transmisión se dificultó la contención inicial ${ }^{21}$. Aunado a ello, el hecho de que la información sobre los contagios/fallecidos y la referente a las vías de transmisión se actualizarán constantemente generó un margen de incertidumbre que impidió una oportuna y contundente evaluación y respuesta de los países ante esta nueva epidemia ${ }^{20}$.

\section{Características del SARS-CoV-2}

Los coronavirus constituyen una gran familia de virus (Coronaviridae) que pueden provocar infecciones tanto en humanos como en animales ${ }^{22,23}$. Los coronavirus pueden clasificarse en cuatro clases: alfa, beta, delta y gamma. Las infecciones de los coronavirus en los seres humanos no acostumbran a causar mayores problemas; sin embargo, las asociadas a los tipo beta han conducido a escenarios sanitarios preocupantes ${ }^{24,25}$. Dos coronavirus tipo beta que emergieron en momentos distintos, en las pasadas dos décadas, alcanzaron tasas de mortalidad superiores al 10\%: el SARS-CoV (coronavirus del síndrome respiratorio agudo grave) y el MERS-CoV (coronavirus del síndrome respiratorio de Medio Oriente $)^{19,23}$. 
El Grupo de Investigación de Coronavirus del Comité Internacional para la Clasificación de los Virus denominó al nuevo coronavirus como SARS-CoV-2 (segundo coronavirus del síndrome respiratorio agudo grave) por su semejanza genética y la proximidad del dominio de unión del receptor (BMD en inglés) al del SARS-CoV (79\%). En efecto, se ha encontrado un porcentaje de similitud del SARS-CoV-2 y los coronavirus de murciélagos cercana al $87-96 \%{ }^{19,26}$. De aquí que es altamente probable que el murciélago sea el huésped original del nuevo coronavirus $^{27}$. Empero, los tres tipos beta de coronavirus difieren en algo: el huésped intermediario ${ }^{19}$.

EI SARS-CoV-2 es un virus ARN monocatenario y polaridad positiva (secuencia de bases del ARN es homóloga a la del ARN mensajero) de aproximadamente 30.000 bases envuelto por una cápsula esférica de 120 a $125 \mathrm{~nm}$ de diámetro ${ }^{24,28,29}$. La capa más externa, o pericápside, consiste en tres glicoproteínas (espiga, envoltura y membrana) y una capa lipídica (figura 1).

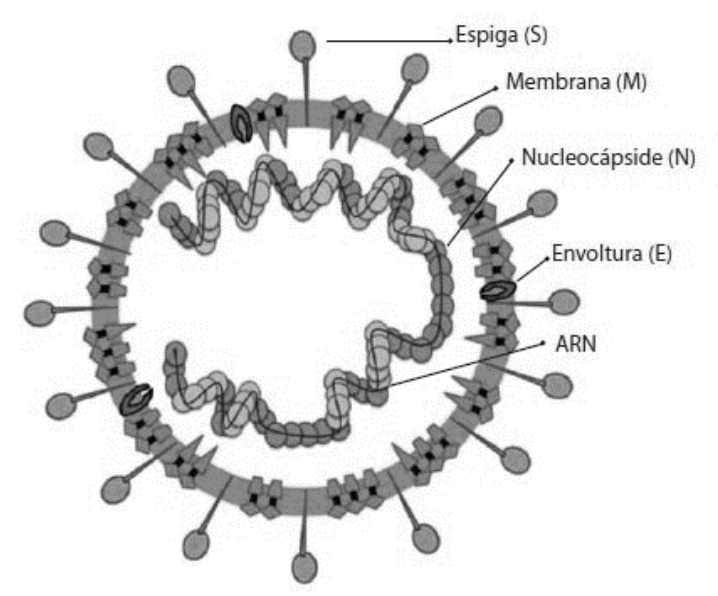

Figura 1. Representación pictórica del SARS-CoV-2 y sus componentes estructurales Fuente: modificada de Quiroz Carrillo et $a l^{29}$.

La espiga tiene dos dominios, uno de los cuales (S1), a través de su BMD, hace que el virus se adhiera a las células humanas para ingresar. La capa interna o nucleocápside es una proteína que envuelve al ARN del virus, proporcionándole protección y estabilidad $^{28}$. Se cree que el motivo por el cual el SARS-CoV-2 es más infeccioso que el SARS-CoV-1 y el MERS-CoV sería su mayor fuerza de adhesión a los receptores de la enzima convertidora de angiotensina 2 (ACE2 en inglés) ${ }^{30}$.

\section{Transmisión del SARS-CoV-2}

Los coronavirus pueden ser encontrados en diferentes especies: mamíferos y aves. Desde el huésped original (murciélagos), saltan a otras especies (gatos, civetas, dromedarios, hurones) que actúan como intermediarias antes de alcanzar a los humanos ${ }^{19,27,31}$.

La transmisión entre el huésped intermediario y los humanos pudo haberse dado a través del consumo de carne, leche, suero o por contacto con sus secreciones $^{19}$. Como los mercados poseen condiciones ideales para la transmisión hacia los humanos ${ }^{19}$, se ha hipotetizado que el primer caso de SARS-CoV-2 pudo haber tenido lugar en el mercado mayorista de mariscos de Wuhan ${ }^{27,31}$. Las evidencias más fuertes indican que el huésped intermediario sería el pangolín ${ }^{19,24,27}$, aunque también se ha sospechado de las serpientes, las tortugas ${ }^{24}$, los gatos o los hurones ${ }^{19}$.

La transmisión del coronavirus entre humanos se da por contacto directo de persona a persona mediante gotas (contacto cercano ${ }^{32}$ ) o aerosoles (inhalación ${ }^{33}$ ) emitidos por una persona infectada y por contacto indirecto de persona a superficie y de superficie a persona donde la primera (animada o inanimada) está contaminada (fómite) ${ }^{25,32-35}$. Entre ambas vías de transmisión, la directa es la más recurrente ${ }^{36,37}$ y difícil de controlar, en particular la inhalación de aerosoles $^{28}$. Gotas emitidas al estornudar, toser, conversar o respirar participan en ambas vías. En la indirecta, la persona necesariamente toca una superficie infectada, por lo que la gota debe caer en esta previamente $^{34}$ (figura 2).

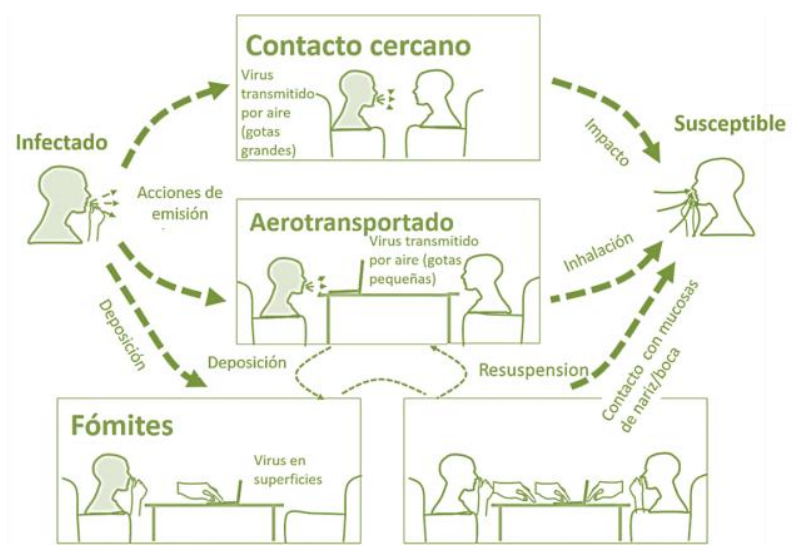


Figura 2. Principales vías de transmisión del coronavirus entre una persona infectada y una susceptible. Fuente: modificada de Tellier et $\left.a\right|^{32}$.

En términos biofísicos, es posible establecer una división entre la vía directa y la indirecta a partir del tamaño de la gota emitida ${ }^{33}$, aunque en la literatura no existe claridad acerca del valor del tamaño crítico $^{28,32,37,38}$. De acuerdo con Jarvis ${ }^{39}$ y Tellier et $a{ }^{\beta 2}$, el diámetro aerodinámico crítico, $d_{c}$, es de 10 $\mu \mathrm{m}$. Asumiendo esto, las gotas grandes $\left(d_{c}>20\right.$ $\mu \mathrm{m})$ tienden a seguir una trayectoria balística como resultado de su mayor inercia (el efecto gravitatorio supera al evaporativo) y son responsables de la vía directa por contacto cercano y en gran parte por la vía indirecta ${ }^{28,32,33,40}$. Por otra parte, las gotas pequeñas $\left(d_{c}<10 \mu \mathrm{m}\right)$, al poseer una inercia menor (el efecto evaporativo supera al gravitatorio), forman aerosoles que permanecen durante varias horas $^{39}$ en el aire y pueden ser transportados por cortas o grandes distancias (formando fómites progresivamente o ser inhalados) ${ }^{33}$. Ahora bien, a pesar de poder llegar a grandes distancias, la dosis de infección de las gotas pequeñas puede reducirse por dispersión ${ }^{39}$. En cuanto a las gotas intermedias (10 $\left.\mu \mathrm{m}<d_{c}<20 \mu \mathrm{m}\right)$, estas se comportan de manera mixta: caen al suelo más rápido que las pequeñas y llevan menos dosis viral que las grandes ${ }^{32}$, dentro de las cuales suelen incluirse $(>10$ $\mu \mathrm{m})^{32}$. En general, cuanto menor es el tamaño de la gota, mayor alcance tiene, aunque en ambientes con flujos cruzados de aire las gotas grandes probablemente realicen largos recorridos. Entretanto, las gotas pequeñas siguen las líneas de flujo laminar de aire ${ }^{32}$.

Otra clasificación consiste en dividir las gotas en inspirables $(>10-100 \mu \mathrm{m})$ y respirables $(<10 \mu \mathrm{m})^{32}$. Las acciones de emisión (toser, estornudar, conversar o respirar) involucran la producción de gotas pequeñas y grandes a partir de la saliva y fluidos del tracto respiratorio profundo. Conversar o respirar puede atomizar las gotas (aerosoles) y al cabo de pocos minutos liberar igual cantidad de volumen que la tos. El volumen total de líquido expulsado depende en esencia de la sonoridad (relacionada con la presión acústica) ${ }^{39}$. Normalmente, cuanto mayor es la gota, más probable es que provenga de las mucosas nasales/bucales, mientras que las pequeñas pueden generarse de la laríngea y la alveolar ${ }^{39}$.

Factores ambientales (temperatura, humedad o iluminación solar) y la velocidad de emisión afectan críticamente el alcance. Menor humedad y temperatura, así como ambientes contaminados, favorecen el contagio y la gravedad de la enfermedad ${ }^{28,33,41-45}$. Por una parte, a menor humedad, más probable es la evaporación y generación de aerosoles, en tanto que, por otra, menor temperatura auspiciaría la permanencia del virus en el aire y en los objetos ${ }^{28,33}$. También se ha asociado una mayor cantidad de horas de iluminación solar a la reducción en la probabilidad de contagio debido a la acción germicida de la franja ultravioleta ${ }^{41-43,46}$. Asimismo, altas concentraciones de material particulado aumentan la morbilidad y mortalidad por COVID-19 al facilitar la introducción del coronavirus en las vías respiratorias y al estimular su unión a las ACE2 por sobreexpresión de estas $^{44,45,47}$.

Con respecto a la velocidad de emisión, se ha observado que el alcance dentro del sistema respiratorio es proporcional a esta ${ }^{28}$ : mientras que las gotas grandes e intermedias no van más allá de la glotis, las gotas finas $\left(d_{c}<5 \mu \mathrm{m}\right)$ pueden llegar hasta los alveolos, asociándose con una mayor progresión e intensidad de la enfermedad ${ }^{32,33,48}$ toda vez que las ACE2 son abundantes en el tracto respiratorio profundo ${ }^{34}$. En la tabla 1 se visualizan algunos de los detalles más importantes acerca de los modos de transmisión del SARS-CoV-2.

Los valores y asociaciones registrados en la tabla 1 son aproximaciones de datos de distintas fuentes, los cuales no siempre coincidían dada la naturaleza variada de los estudios.

\section{Sintomatología e infecciosidad del SARS-CoV-2}

La descripción de los primeros cuadros clínicos de COVID-19 se produjo entre diciembre de 2019 y enero de 2020 en China ${ }^{29}$. Los reportes señalaban como principales síntomas: fiebre, tos seca, fatiga, disnea, vómitos y diarrea $22,25,29,31$, siendo los dos primeros, en orden, los más recurrentes ${ }^{25,31}$. No 
obstante, el orden de la sintomatología puede variar entre los países $(1-7 \%)^{22,50}$.

El periodo de incubación del SARS-CoV-2 varía de 114 días $^{51}$. Por esto, personas infectadas asintomáticas son capaces de transmitirlo ${ }^{25}$. Sin embargo, se ha estimado que las presintomáticas y sintomáticas son más proclives a propagar la infección ${ }^{37}$. Adicionalmente, se ha visto que el momento de mayor gravedad se presenta 10 días después del inicio de síntomas ${ }^{51}$.

Tabla 1. Resumen de las características de las gotas y su asociación con el alcance y acciones de emisión ${ }^{33,37,39,49}$.

\begin{tabular}{|c|c|c|c|c|c|c|}
\hline \multicolumn{2}{|l|}{ Vía de transmisión } & $\begin{array}{l}\text { Tamaño de la gota } \\
\text { emitida }(\boldsymbol{\mu m})\end{array}$ & $\begin{array}{l}\text { Relación } \\
\text { sedimentación } \\
\text { (gravedad)/evapor } \\
\text { ación }\end{array}$ & $\begin{array}{l}\text { Principal acción de } \\
\text { emisión de la gota } \\
\text { mínima para alcance }\end{array}$ & $\begin{array}{l}\text { Velocidad } \\
\text { de emisión } \\
\text { de la gota } \\
(\mathbf{m} / \mathbf{s})\end{array}$ & $\begin{array}{l}\text { Alcance } \\
\text { de } \\
\text { partícula } \\
(\mathbf{m})\end{array}$ \\
\hline \multirow{2}{*}{ Lirecta } & $\begin{array}{c}\text { Contacto } \\
\text { cercano }\end{array}$ & $>10-20$ & $>>1$ & Toser o estornudar & $>1-5$ & $<1-2$ \\
\cline { 2 - 7 } & Inhalación & $<5-10$ & $<<1$ & Conversar o respirar & $1-50$ & $<1$ a $>>2$ \\
\hline Indirecta & Fómites & $>20$ & $\geq 1$ & Toser o estornudar & $4-50$ & $>1-2$ \\
\hline
\end{tabular}

Por otra parte, se ha constatado que cerca del $80 \%$ de los contagiados se recupera sin necesidad de internación hospitalaria y solo poco más del $5 \%$ ingresan a $\mathrm{UCl}$. Empero, personas con comorbilidades (ej., hipertensión, obesidad, diabetes, VIH o cáncer) tienden a desarrollar cuadros graves de la enfermedad que en ocasiones desembocan en la muerte ${ }^{22,52}$. Ser adulto mayor (>60 años) también se ha relacionado con aumento de letalidad ${ }^{2,50,52}$.

La dosis de infección se refiere a la capacidad de un patógeno para infectar a un individuo sano². Por tanto, cuanto menor es el valor de la dosis mínima para infección, más infeccioso será el patógeno ${ }^{53}$. La unidad de medida de esta dosis es la ID50 o dosis para infectar al $50 \%$ de individuos de una población susceptible. EI SARS-CoV-2 es evidentemente más contagioso que sus antecesores², lo que obedecería a la posibilidad de que los asintomáticos transmitan el virus, las altas dosis del actual coronavirus en el tracto respiratorio ${ }^{24}$ y una divergencia en el acople molecular del virus en las células, mencionada en una sección anterior.

Van Damme et $a l^{53}$ han teorizado que la dosis de infección se correlaciona positivamente con la transmisibilidad y gravedad de la enfermedad. Así: i) una persona con baja dosis desarrollará síntomas leves en comparación con aquella con alta dosis y viceversa, independientemente de comorbilidades - la edad; ii) una persona asintomática o con sintomatología leve, por su menor dosis de infección, difícilmente transmitirá el patógeno y, de hacerlo, aquella contagiada desarrollará un cuadro clínico igualmente leve, lo cual crea grupos con sintomatología leve; iii) en determinados contextos, influenciados por factores climáticos y la densidad de habitantes, grupos graves de personas pueden promover una alta transmisión del virus, con síntomas graves, a otras susceptibles.

Para explicar tal correlación, los autores propusieron que dosis bajas del virus inducen cascadas de respuestas inmunitarias capaces de eliminar al SARS-CoV-2 y/o estimulan una respuesta inmune protectora que resulte a una sintomatología leve. Entretanto, a dosis altas, el virus evadirá la respuesta inmune y/o provocará una respuesta caótica del sistema inmunológico que agrava aún más el cuadro clínico ${ }^{53}$.

\section{Medidas de salud pública contra la COVID-19}

Ante el surgimiento repentino de una nueva epidemia como la COVID-19, es esperable que no exista una solución farmacológica eficaz a corto plazo ni vacunas, y que los recursos sanitarios no sean suficientes para tratar a todos los infectados $^{9,54}$. En consecuencia, es mandatorio 
poner en marcha intervenciones no farmacéuticas (NIP en inglés: non-pharmaceutical interventions), es decir, medidas de salud pública que intentan prevenir, mitigar o suprimir las consecuencias de la epidemia ${ }^{3,14}$.

Las medidas de prevención (o contención) tienen como fin impedir la transmisión de la enfermedad para evitar su propagación y el colapso del sistema de atención en salud, mientras se desarrolla algún tratamiento efectivo o una vacuna ${ }^{3,14}$. Constituyen la primera barrera contra la enfermedad y deben ser rápidamente empleadas ${ }^{22}$. Por su parte, las medidas de mitigación buscan reducir la mortalidad de la epidemia y el colapso del sistema de salud cuando aumenta el número de casos. Las medidas de supresión, finalmente, se proponen reducir los casos secundarios $^{14}$ (esto es, que el número de reproducción efectiva sea menor que uno ${ }^{3}$ ).

Dentro de las políticas públicas contra la pandemia en Colombia ${ }^{55}$ y otros países de Latinoamérica ${ }^{56-60}$, se destacaron, inicialmente, el confinamiento generalizado de la población y la atención de urgencias. Seguidamente, y en consonancia con la evolución de la tasa de contagios y fallecidos, se transitó hacia un confinamiento inteligente o sectorizado, para promover la reactivación gradual de la economía ${ }^{61}$. Se aplicaron, por lo general, las recomendaciones de la OMS aunque en diferentes momentos, con flexibilidad variable en la exigencia ${ }^{14}$. A continuación, algunas de ellas:

1. Lavado de manos: esta medida busca prevenir la transmisión indirecta del virus por contacto con superficies inanimadas (objetos en los que se han asentado gotas contaminadas) (figura 2). La justificación radica en el hecho de que el coronavirus puede persistir de horas a días en superficies sólidas ${ }^{28}$. Por tanto, se recomienda restregar las manos en soluciones jabonosas durante 30 s o $1 \mathrm{~min}^{34}$ o con alcohol en gel al $70 \%$ o más. Se sugiere la primera cuando las manos están visiblemente sucias ${ }^{34}$, y se debe considerar la segunda al salir a lugares públicos, aún más al aire libre, por practicidad.

Las soluciones jabonosas actúan fragmentando la membrana glicoproteíca cuando las colas hidrófobas del jabón interactúan con las del coronavirus. El friegue de manos acelera el proceso al inducir fuerzas de cizalla que aceleran la fragmentación de la membrana. Finalmente, el flujo de agua retira las micelas por convección ${ }^{33}$. El alcohol, por su parte, promueve la desnaturalización de las proteínas y la disolución de los lípidos de la membrana del coronavirus cuando sus oxígenos polares debilitan las interacciones lipofílicas ${ }^{62}$.

2. Distanciamiento social (cuarentena): se refiere al confinamiento obligatorio de las personas en sus hogares. Este busca evitar que individuos susceptibles estén expuestos al virus. Tomando en cuenta modelos epidemiológicos como el SIR, el distanciamiento social actúa disminuyendo el número de contactos del individuo infectado $y$ así el número efectivo de reproducción ${ }^{63}$.

La aplicación de esta medida ha mostrado disminuir la infectividad del coronavirus ${ }^{14,15,64}$ y aumentar la capacidad médica ${ }^{65}$. No obstante, esta estrategia conlleva un costo socioeconómico y psicológico enorme debido al cierre de instituciones educativas, establecimientos comerciales, iglesias, aeropuertos y fronteras, así como la prohibición de eventos públicos entre otros ${ }^{3,14}$. Todo esto fue aplicado por igual en toda Latinoamérica ${ }^{15}$.

3. Distanciamiento físico: consiste en mantener una distancia prudencial entre los individuos que circulan en ambientes públicos, asumiendo razonablemente que todos son potenciales fuentes de contagio. El distanciamiento físico minimiza la transmisión directa del virus ${ }^{28}$ y con ello la disminución de la probabilidad de contagio ${ }^{63}$. Sin embargo, como los aerosoles pueden desplazarse grandes distancias $y$ pervivir por varias horas en aire, se requieren elementos de protección personal (EPP) ${ }^{3,28,33}$.

El principal EPP es la máscara ${ }^{28,33,49}$, pero existen otros como visores o guantes, muy demandados en ciertos escenarios ${ }^{25,36}$. Las máscaras $\mathrm{N} 95$ y quirúrgicas, en particular, desempeñan un importante papel en la protección contra aerosoles contaminados. Así, aunque hay resultados contradictorios, lo más probable es que las N95 sean más eficaces ${ }^{53}$, si bien son más costosas. La capacidad de filtrado de estas máscaras las hace imprescindibles en espacios con acciones de fuertes 
emisiones (toser o estornudar). Por tal razón, y en virtud del riesgo, se aconseja restringir su uso al personal médico $28,32,33,49$.

Asegurar un buen ajuste de las máscaras al contorno facial es de suma importancia para evitar filtraciones laterales y flujos secundarios aerolizados ${ }^{28,33}$. Además, se ha mostrado que cuando individuos infectados o sanos portan máscaras se reduce más de 10 veces la dosis de infección en el ambiente ${ }^{53,66}$. Las máscaras deben ser diseñadas para no permitir el ingreso de partículas menores a $50{\mu m^{28}}^{28}$ por inhalación, ya que por encima de ese tamaño impactan con las fibras $^{33}$. En hospitales, ante distanciamientos físicos restrictivos, ha sido importante el uso de filtros purificadores de aire y ventiladores de presión negativa ${ }^{2,33}$. El distanciamiento físico, acompañado de máscaras, fue también adoptado en Latinoamérica ${ }^{15}$.

4. Rastreo, testeo masivo, cerco epidemiológico, aislamiento individual y cuarentena inteligente: es el engranaje de medidas que propenden a buscar e identificar individuos contagiados y focos de infección, delimitar geográficamente las zonas de alto contagio, y cercar o aislar personas que han dado positivo a la prueba y a aquellos con quienes tuvieron contacto en días anteriores ${ }^{3,14,15,67}$. Estas medidas, junto con la cuarentena, han mostrado mitigar la transmisión ${ }^{65}$. Además, fueron rutinariamente aplicadas en países de la región $n^{15}$.

La cuarentena inteligente pretendía flexibilizar y/o sectorizar las restricciones de movilidad pública según el comportamiento de la curva de contagio. Varios países latinoamericanos adoptaron esta medida poco tiempo después de la obligatoria, para promover la reactivación de la economía ${ }^{15}$.

5. Descontaminación por luz ultravioleta (UV), termometría infrarroja y tecnologías digitales de alerta: durante la pandemia se ha explorado la aplicación de UV lejana (222 nm) para garantizar un desconfinamiento seguro sobre la base de que esta no causaría daños en la piel humana. En países como Colombia ${ }^{68}$ y Brasil ${ }^{69}$ se han realizado estudios pilotos para emplear esta tecnología en hospitales, siguiendo el ejemplo de Estados Unidos ${ }^{70}$. Un estudio realizado en Brasil mostró una relación inversa entre la UV solar y la infectividad del SARS-CoV$2^{64}$. Asimismo, se emplearon termómetros y cámaras infrarrojas como medidas de detección temprana de sospechosos, sobre la base de haber resultado útiles en epidemias anteriores, ser indoloros y rápidos, y tener algún efecto positivo en la contención del brote $^{71}$.

Tecnologías digitales constan de aplicativos en los que se visualizan las zonas con algún tipo de riesgo de contagio, así como el registro de sintomatología relacionada con la COVID-19. La coordinación y la gestión de datos requerida para la implementación de medidas de control epidémico en los países se han basado en tales tecnologías ${ }^{72}$. Su uso pretende auspiciar el aplanamiento de la curva de contagio y mantener informada y capacitada a la población en medidas de prevención ${ }^{73}$. China fue el primer país en diseñar una app de rastreo de contactos y monitoreo de síntomas, y le siguieron otros países asiáticos y europeos ${ }^{73}$. En Latinoamérica también se han realizado esfuerzos en esa línea ${ }^{74}$. La tabla 2 condensa las medidas para reducir el contagio por COVID-19.

Los países que han sostenido mínimas tasas de mortalidad por habitante de COVID-19 parecen compartir estrategias que incluyen vigilancia temprana, pruebas, rastreo de contactos y cuarentena obligatoria los primeros meses. En estos casos se han integrado tecnologías digitales a esas estrategias ${ }^{72}$.

Finalmente, cabe considerar que las acciones de mitigación/prevención/supresión no siguen un curso temporal lineal en el sentido en que se inicia siempre con una de ellas y se termina con otra, sino que se van adoptando según las necesidades del contexto. 
Tabla 2. Medidas para contrarrestar la COVID-19, sus ventajas y desventajas.

\begin{tabular}{|c|c|c|c|}
\hline Medidas & Descripción & Ventajas & Desventajas \\
\hline Mitigación & $\begin{array}{l}\text { Cuarentena inteligente y } \\
\text { distanciamiento físico. } \\
\text { Rastreo, cerco epidémico, } \\
\text { aislamiento individual, uso } \\
\text { de herramientas } \\
\text { tecnológicas. }\end{array}$ & $\begin{array}{l}\text { Control sectorizado y } \\
\text { seguimiento continuo. } \\
\text { Reactiva la economía. }\end{array}$ & $\begin{array}{l}\text { Coordinación de actividades } \\
\text { entre distintos sectores. }\end{array}$ \\
\hline Contención & $\begin{array}{l}\text { Lavado de manos, evitar } \\
\text { espacios densamente } \\
\text { poblados y poco ventilados, } \\
\text { uso de máscaras. }\end{array}$ & $\begin{array}{lr}\text { Fáciles de } & \text { aplicar. } \\
\text { Aprendizaje y tecnología } \\
\text { para futuros } & \text { brotes. } \\
\text { Transición } & \text { a } \\
\text { desconfinamiento seguro e } \\
\text { incorporación de medidas } \\
\text { digitales para vigilancia } \\
\text { pública. }\end{array}$ & $\begin{array}{l}\text { Depende de la disciplina de } \\
\text { los ciudadanos. }\end{array}$ \\
\hline Supresión & $\begin{array}{l}\text { Cuarentena obligatoria: } \\
\text { cierre de establecimientos } \\
\text { (escuelas, } \\
\text { comercio, aeropuertos). } \\
\text { Aislamiento (o negación de } \\
\text { ingreso) de viajeros } \\
\text { provenientes de países que } \\
\text { presentaron los primeros } \\
\text { brotes de la enfermedad o } \\
\text { con crecimiento } \\
\text { descontrolado. }\end{array}$ & $\begin{array}{l}\text { Control efectivo de la } \\
\text { epidemia y cese progresivo } \\
\text { de la transmisión. } \\
\text { Tiempo para conocer la } \\
\text { epidemia. Evitar colapso del } \\
\text { sistema sanitario. }\end{array}$ & $\begin{array}{l}\text { Insostenible } \\
\text { económicamente. } \\
\text { Incremento de problemas } \\
\text { sociales y psicológicos. } \\
\text { Ayudas económicas } \\
\text { (aumento del gasto } \\
\text { público). }\end{array}$ \\
\hline
\end{tabular}

\section{CONCLUSIÓN}

La COVID-19 ha representado un desafío mundial en el cuidado de la salud y el bienestar económico sin precedentes ante la falta de vacuna y tratamiento efectivo. De acuerdo con el curso de la epidemia, se tomaron diversas medidas de control que trabajan en función del número de casos y fallecidos; en otras palabras, de los seguimientos realizados en las comunidades. Algunas de las medidas más prometedoras como complemento a las tradicionales son: herramientas tecnológicas de rastreo, recomendación de higiene constante y luz ultravioleta lejana para el retorno seguro.

Es probable que los países que han mostrado mejores resultados en la lucha contra la pandemia sean aquellos que iniciaron con cuarentena obligatoria y medidas de higiene al inicio, para después transitar a una cuarentena inteligente o sectorizada con vigilancia pública estricta y soportada en herramientas tecnológicas, todo esto de manera mancomunada. Con todo, queda pendiente establecer el costo/beneficio de medidas de supresión como la cuarentena en la salud psíquica y social, así como en la economía de las naciones.

\section{DECLARACIÓN SOBRE CONFLICTO DE INTERESES}

Los autores declaran que no existe conflicto de intereses. 


\section{CONTRIBUCIÓN DE LOS AUTORES}

Primer autor: conceptualización, redacción y diseño metodológico.

Segundo autor: diseño metodológico, redacción y revisión final.

Tercer autor: redacción y diseño metodológico.

\section{REFERENCIAS BIBLIOGRÁFICAS}

1. Ochoa-Rosales C, González-Jaramillo N, VeraCalzaretta A, Franco $\mathrm{OH}$. Impacto de diferentes medidas de mitigación en el curso de la pandemia de COVID-19 en Chile: proyección preliminar para el período del 14 de abril al 14 de mayo. Rev Salud Pública [revista en la Internet]. 1 de marzo de 2020; 22(2): 1-6. Disponible en: https://revistas.unal.edu.co/index.php/revsaludpu blica/article/view/86380

2. Schröder I. COVID-19: A Risk Assessment Perspective. ACS Chem Heal Saf [revista en la Internet]. 26 de mayo de 2020; 27(3): 160-9. Disponible en: https://pubs.acs.org/doi/10.1021/acs.chas.0c0003 5

3. Ferguson N, Laydon D, Nedjati-Gilani G, Imai N, Ainslie $\mathrm{K}$, Baguelin $\mathrm{M}$, etal. Impact of nonpharmaceutical interventions (NPIs) to reduce COVID-19 mortality and healthcare demand [Internet]. Londres, Reino Unido: Imperial College. COVID Response Team; 2020. Disponible en: https://www.imperial.ac.uk/mrc-global-infectiousdisease-analysis/covid-19/report-9-impact-of-npison-covid-19/

4. Ministerio de Salud y Protección Social. Abecé: Nuevo coronavirus (COVID-19) de China [Internet]. 2020 [citado 5 de febrero de 2021]. p. 5. Disponible en:

https://www.minsalud.gov.co/sites/rid/Lists/Bibliot ecaDigital/RIDE/VS/PP/ET/abece-coronavirus.pdf

5. Organización Mundial de la Salud. La OMS caracteriza a COVID-19 como una pandemia [Internet]. 2020 [citado 10 de agosto de 2020]. Disponible en: https://www.paho.org/hq/index.php?option=com_ content \&view=article\&id=15756: who- characterizes-covid-19-as-a-

pandemic\&ltemid=1926\&lang=es

6. Manrique Abril FG, Agudelo Calderón CA, González Chordá VM, Gutiérrez Lesmes O, Téllez Piñerez CF, Herrera Amaya G. Modelo SIR de la pandemia de COVID-19 en Colombia. Rev Salud Pública [revista en la Internet]. 2020; 22(2): 1-9. Disponible en: https://revistas.unal.edu.co/index.php/revsaludpu blica/article/view/8597

7. RTVE. El mapa mundial del coronavirus: 105 millones de casos y más de 2,2 millones de muertos en todo el mundo [Internet]. 2021 [citado 4 de febrero de 2021]. p. 1. Disponible en: https://www.rtve.es/noticias/20210205/mapamundial-del-coronavirus/1998143.shtml

8. Madhav N, Oppenheim B, Gallivan $M$, Mulembakani P, Rubin E, Wolfe N. Pandemics: Risks, Impacts, and Mitigation. En: Jamison D, Gelband $H$, Horton S, Jha P, Laxminarayan R, Mock $\mathrm{C}$ et al., editores. Disease Control Priorities. Third Edition (Volume 9): Improving Health and Reducing Poverty [Internet]. The World Bank; 2017. p. 315-45. Disponible en: http://elibrary.worldbank.org/doi/10.1596/978-14648-0527-1_ch17

9. Lai S, Ruktanonchai NW, Zhou L, Prosper O, Luo $W$, Floyd $J R$, et al. Effect of non-pharmaceutical interventions to contain COVID-19 in China. Nature [revista en la Internet]. 17 de septiembre de 2020; 585(7825): 410-3. Disponible en: http://www.nature.com/articles/s41586-020-2293$x$

10. Instituto de Efectividad Clínica y Sanitaria. Intervenciones no farmacológicas de salud pública en la pandemia por COVID-19. [Internet]. 2020 [citado 5 de febrero de 2021]. p. 18. Disponible en: https://docs.bvsalud.org/biblioref/2020/06/110025 2/iecs-irr-775-va-intervenciones-no-

farmacologicas-covid-19-1.pdf

11. Varano Jl. Estrategias y desafíos de la industria musical en tiempos pandemia y virtualidad. Question/Cuestión [revista en la Internet]. 15 de 
mayo de 2020; 1(mayo): e306. Disponible en: https://perio.unlp.edu.ar/ojs/index.php/question/a rticle/view/5984

12. Schijman A, Correa C, Vera-Cossio D. COVID-19: las medidas de contención y la confianza [Internet]. 22 de enero de 2021 [citado 6 de febrero de 2021]. p. 1. Disponible en: https://blogs.iadb.org/ideasque-cuentan/es/covid-19-las-medidas-decontencion-y-la-confianza/

13. Verdes-Montenegro FJ. Excepcionalidad y COVID-19: Un test democrático para América Latina. Análisis Carolina [Internet]. 9 de junio de 2020. Disponible en: https://www.fundacioncarolina.es/ac-34-2020/

14. Patiño-Lugo DF, Velez $M$, Velásquez Salazar $P$, Vera-Giraldo CY, Vélez V, Marín IC, et al. Nonpharmaceutical interventions for containment, mitigation and suppression of COVID-19 infection. Colomb Med [revista en la Internet]. 26 de mayo de 2020; 51(2): e-4266. Disponible en: https://colombiamedica.univalle.edu.co/index.php /comedica/article/view/4266

15. Giovanella L, Vega $R$, Tejerina-Silva $H$, AcostaRamirez N, Parada-Lezcano M, Ríos G, et al. ¿Es la atención primaria de salud integral parte de la respuesta a la pandemia de Covid-19 en Latinoamérica? Trab Educ e Saúde [revista en la Internet]. Enero de 2021; 19. Disponible en: http://www.scielo.br/scielo.php?script=sci_arttext \&pid=S1981-77462021000100402\&tIng=es

16. Aguilar Cordero MJ, Sánchez López AM, Guisado Barrilao R, Rodriguez Blanque R, Noack Segovia J, Pozo Cano MD. Descripción del acelerómetro como método para valorar la actividad física en los diferentes periodos de la vida; revisión sistemática. Nutr Hosp. 2014; 29(6): 1250-61.

17. Silva L, Figueiredo Filho D. Using Benford's law to assess the quality of COVID-19 register data in Brazil. J Public Health (Bangkok) [revista en la Internet]. 24 de octubre de 2020; 43(1): 107-10. Disponible en: https://academic.oup.com/jpubhealth/advancearticle/doi/10.1093/pubmed/fdaa193/5937152
18. Walker $\mathrm{P}$, Whittaker $\mathrm{C}$, Watson $\mathrm{O}$, Baguelin $\mathrm{M}$, Ainslie KEC, Bhatia S, et al. Reporte 12: El impacto global de COVID-19 y estrategias para la mitigación y supresión. Imp Coll London [revista en la Internet]. 2020; (March): 1-19. Disponible en: https://doi.org/10.25561/77735

19. Liu J, Xie W, Wang Y, Xiong Y, Chen S, Han J, et al. A comparative overview of COVID-19, MERS and SARS: Review article. Int J Surg [revista en la Internet]. Septiembre de 2020; 81: 1-8. Disponible en:

https://linkinghub.elsevier.com/retrieve/pii/S1743 919120305677

20. Huamaní C, Timaná-Ruiz R, Pinedo J, Pérez J, Vásquez L. Condiciones estimadas para controlar la pandemia de COVID-19 en escenarios de pre y poscuarentena en el Perú. Rev Peru Med Exp Salud Pública. 2020; 37(2): 195-202.

21. Morawska L, Cao J. Airborne transmission of SARS-CoV-2: The world should face the reality. Environ Int [revista en la Internet]. Junio de 2020; 139: 105730.1 Disponible en: https://linkinghub.elsevier.com/retrieve/pii/S0160 41202031254X

22. Matus-Abásolo CP, Nemeth-Kohanszky ME, Inostroza-Tapia MA. Atención de Pacientes en Tratamiento de Ortodoncia Durante la Pandemia COVID-19 (SARS-CoV-2). Presentación de un Algoritmo. Int J Odontostomatol [revista en la Internet]. Diciembre de 2020; 14(4): 489-94. Disponible en: http://www.scielo.cl/scielo.php?script=sci_arttext \&pid=S0718-

$381 X 2020000400489 \& \operatorname{lng}=e n \& n r m=i s o \& \operatorname{lng}=e n$

23. Fernández D, Alonso LM, Fernández JA, Ordás B, Martínez S. Todo lo que necesitas saber del Coronavirus. Tiempos Enfermería y Salud [revista en la Internet]. 2019; 2(7): 1-10. Disponible en: https://tiemposdeenfermeriaysalud.es/journal/arti cle/view/73/60

24. Ruiz-Bravo A, Jiménez-Valera M. SARS-CoV-2 y pandemia de síndrome respiratorio agudo (COVID19). Ars Pharm [revista en la Internet]. 2020; 61(2): 63-79. Disponible en: 
Aspectos biofísicos de la transmisión del SARS-CoV-2 y medidas para contrarrestar la COVID-19: una revisión integral

http://scielo.isciii.es/scielo.php?script=sci_arttext\& pid $=$ S2340-98942020000200001

25. Fallahi HR, Keyhan SO, Zandian D, Kim S-G, Cheshmi B. Being a front-line dentist during the Covid-19 pandemic: a literature review. Maxillofac Plast Reconstr Surg [revista en la Internet]. 24 de diciembre de 2020; 42(1): 12. Disponible en: https://pubmed.ncbi.nlm.nih.gov/32341913/

26. Wang $\mathrm{H}$, Li X, Li T, Zhang S, Wang L, Wu X, et al. The genetic sequence, origin, and diagnosis of SARS-CoV-2. Eur J Clin Microbiol Infect Dis [revista en la Internet]. 24 de septiembre de 2020; 39(9): 1629-35. Disponible en: http://link.springer.com/10.1007/s10096-02003899-4

27. Dhama K, Patel SK, Sharun K, Pathak M, Tiwari R, Yatoo $\mathrm{MI}$, et al. SARS-CoV-2 jumping the species barrier: Zoonotic lessons from SARS, MERS and recent advances to combat this pandemic virus. Travel Med Infect Dis [revista en la Internet]. Septiembre de 2020; 37: 101830. Disponible en: https://linkinghub.elsevier.com/retrieve/pii/S1477 893920303264

28. Seminara G, Carli B, Forni G, Fuzzi S, Mazzino A, Rinaldo A. Biological fluid dynamics of airborne COVID-19 infection. Rend Lincei Sci Fis e Nat [revista en la Internet]. 16 de agosto de 2020; 31(3): 505-37. Disponible en: http://link.springer.com/10.1007/s12210-02000938-2

29. Quiroz Carrillo CG, Pareja Cruz A, Valencia Ayala E, Enriquez Valencia YP, De Leon Delgado J, Aguilar Ramirez P. Un nuevo coronavirus, una nueva enfermedad: COVID-19. Horiz Médico [revista en la Internet]. 30 de junio de 2020; 20(2): e1208. Disponible en: http://www.horizontemedico.usmp.edu.pe/index.p $\mathrm{hp} /$ horizontemed/article/view/1208

30. Tai W, He L, Zhang X, Pu J, Voronin D, Jiang S, et al. Characterization of the receptor-binding domain (RBD) of 2019 novel coronavirus: implication for development of RBD protein as a viral attachment inhibitor and vaccine. Cell $\mathrm{Mol}$ Immunol [revista en la Internet]. 19 de junio de
2020; 17(6): 613-20. Disponible en: http://www.nature.com/articles/s41423-020-04004

31. Zepeda F. G, Tapia F. L, Ortiz F. P. Infección por SARS-CoV-2 y enfermedad por coronavirus-2019 en pediatría. Rev Chil Enfermedades Respir [revista en la Internet]. Junio de 2020; 36(2): 122-32. Disponible en:

http://www.scielo.cl/scielo.php?script=sci_arttext \&pid=S0717-

$73482020000200122 \& \operatorname{lng}=e n \& n r m=i s o \& t \mid n g=e n$

32. Tellier R, Li Y, Cowling BJ, Tang JW. Recognition of aerosol transmission of infectious agents: a commentary. BMC Infect Dis [revista en la Internet]. 31 de enero de 2019; 19(1): 101. Disponible en: https://bmcinfectdis.biomedcentral.com/articles/1 0.1186/s12879-019-3707-y

33. Mittal R, Ni R, Seo J-H. The flow physics of COVID19. J Fluid Mech [revista en la Internet]. 10 de julio de 2020; 894: F2-1-F2-14. Disponible en: https://www.cambridge.org/core/product/identifie r/S0022112020003304/type/journal_article

34. Guiñez-Coelho M. Impacto del COVID-19 (SARSCoV-2) a Nivel Mundial, Implicancias y Medidas Preventivas en la Práctica Dental y sus Consecuencias Psicológicas en los Pacientes. Int J Odontostomatol [revista en la Internet]. Septiembre de 2020; 14(3): 271-8. Disponible en: http://www.scielo.cl/scielo.php?script=sci_arttext \&pid=S0718-

$381 \times 2020000300271 \& \operatorname{lng}=e n \& n r m=i s o \& \operatorname{lng}=e n$

35. Morawska L, Tang JW, Bahnfleth W, Bluyssen PM, Boerstra A, Buonanno $G$, et al. How can airborne transmission of COVID-19 indoors be minimised? Environ Int. Septiembre de 2020; 142: 105832.

36. Martins-Filho PR, Gois-Santos VT, Tavares CSS, Melo EGM de, Nascimento-Júnior EM do, Santos VS. Recommendations for a safety dental care management during SARS-CoV-2 pandemic. Rev Panam Salud Pública [revista en la Internet]. 2020; 44(e51): 1-7. Disponible en: https://iris.paho.org/handle/10665.2/51999 
37. Vuorinen V, Aarnio M, Alava M, Alopaeus V, Atanasova N, Auvinen $M$, et al. Modelling aerosol transport and virus exposure with numerical simulations in relation to SARS-CoV-2 transmission by inhalation indoors. Saf Sci [revista en la Internet]. Octubre de 2020; 130: 104866. Disponible en: https://linkinghub.elsevier.com/retrieve/pii/S0925 753520302630

38. Jayaweera M, Perera H, Gunawardana B, Manatunge J. Transmission of COVID-19 virus by droplets and aerosols: A critical review on the unresolved dichotomy. Environ Res [revista en la Internet]. Septiembre de 2020; 188: 109819. Disponible

en: https://linkinghub.elsevier.com/retrieve/pii/S0013 935120307143

39. Jarvis MC. Aerosol Transmission of SARS-CoV-2: Physical Principles and Implications. Front Public Heal [revista en la Internet]. 23 de noviembre de 2020; 8: $590041 . \quad$ Disponible en: https://www.frontiersin.org/articles/10.3389/fpub h.2020.590041/full

40. Gorbunov B. Aerosol Particles Laden with COVID19 Travel Over 30m Distance. Preprints [revista en la Internet]. 2020; 1-18. Disponible en: https://www.preprints.org/manuscript/202004.054 $6 / v 1$

41. Ratnesar-Shumate $S$, Williams $G$, Green B, Krause $M$, Holland $B$, Wood $S$, et al. Simulated Sunlight Rapidly Inactivates SARS-CoV-2 on Surfaces. J Infect Dis [revista en la Internet]. 2020; 222(2): 214-22. Disponible en: https://academic.oup.com/jid/article/222/2/214/5 841129

42. Guasp M, Laredo C, Urra X. Higher Solar Irradiance is Associated With a Lower Incidence of Coronavirus Disease 2019. Clin Infect Dis [revista en la Internet]. 19 de mayo de 2020; 71(16): 2269-71. Disponible en:

https://academic.oup.com/cid/advancearticle/doi/10.1093/cid/ciaa575/5840498

43. Schuit M, Ratnesar-Shumate $S$, Yolitz J, Williams G, Weaver W, Green B, et al. Airborne SARS-CoV-2 Is Rapidly Inactivated by Simulated Sunlight. J Infect
Dis [revista en la Internet]. 23 de julio de 2020; 222(4): 564-71. Disponible en: https://academic.oup.com/jid/article/222/4/564/5 856149

44. Tung NT, Cheng P-C, Chi $\mathrm{K}-\mathrm{H}$, Hsiao T-C, Jones $\mathrm{T}$, BéruBé $\mathrm{K}$, et al. Particulate matter and SARS-CoV-2: A possible model of COVID-19 transmission. Sci Total Environ [revista en la Internet]. Enero de 2021; 750: $141532 . \quad$ Disponible en: https://linkinghub.elsevier.com/retrieve/pii/S0048 969720350610

45. Comunian S, Dongo D, Milani C, Palestini P. Air Pollution and COVID-19: The Role of Particulate Matter in the Spread and Increase of COVID-19's Morbidity and Mortality. Int J Environ Res Public Health [revista en la Internet]. 22 de junio de 2020; 17(12): 4487.4 Disponible en: https://www.mdpi.com/1660-4601/17/12/4487

46. Cabrera Morales CM, López-Nevot MA. Efectos de la radiación ultravioleta (UV) en la inducción de mutaciones de p53 en tumores de piel. Oncol [revista en la Internet]. Septiembre de 2006; 29(7): 25-32. Disponible en: http://scielo.isciii.es/scielo.php?script=sci_arttext\& pid $=$ S0378-

48352006000700003\&lng=en\&nrm=iso\&tlng=en

47. Borro M, Di Girolamo P, Gentile G, De Luca O, Preissner R, Marcolongo A, et al. Evidence-Based Considerations Exploring Relations between SARSCoV-2 Pandemic and Air Pollution: Involvement of PM2.5-Mediated Up-Regulation of the Viral Receptor ACE-2. Int J Environ Res Public Health [revista en la Internet]. 2 de agosto de 2020; 17(15): 5573. Disponible en: https://www.mdpi.com/16604601/17/15/5573

48. Weinbaum S, Fu B, Kayser H. COVID-19 aerosols and droplets and their entry into lung alveoli. Arch Biomed Sci Eng [revista en la Internet]. 15 de septiembre de 2020; 041-2. Disponible en: https://www.peertechz.com/articles/ABSE-6120.php

49. Agrawal A, Bhardwaj R. Reducing chances of COVID-19 infection by a cough cloud in a closed space. Phys Fluids [revista en la Internet]. 1 de 
octubre de 2020; 32(10): 101704. Disponible en: http://aip.scitation.org/doi/10.1063/5.0029186

50. Grillo-Ardila EK, Bravo LE. Análisis de mortalidad por COVID-19 en Colombia: Medidas de ocurrencia. Univ y Salud [revista en la Internet]. 10 de diciembre de 2020; 22(3): 292-8. Disponible en: https://revistas.udenar.edu.co/index.php/usalud/a rticle/view/5917

51. Wilder-Smith A, Chiew CJ, Lee VJ. Can we contain the COVID-19 outbreak with the same measures as for SARS? Lancet Infect Dis [revista en la Internet]. Mayo de 2020; 20(5): e102-7. Disponible en: https://linkinghub.elsevier.com/retrieve/pii/S1473 309920301298

52. Aquino-Canchari CR, Quispe-Arrieta $R$ del $C$, Castillon KMH. COVID-19 y su relación con poblaciones vulnerables. Rev Habanera Ciencias Médicas [revista en la Internet]. 2020; 19 (Suple)(e3341): 1-18. Disponible en: http://www.revhabanera.sld.cu/index.php/rhab/ar ticle/view/3341

53. Van Damme W, Dahake R, van de Pas R, Vanham G, Assefa Y. COVID-19: Does the infectious inoculum dose-response relationship contribute to understanding heterogeneity in disease severity and transmission dynamics? Med Hypotheses [revista en la Internet]. Enero de 2021; 146: 110431. Disponible en:

https://linkinghub.elsevier.com/retrieve/pii/S0306 987720333223

54. San Martín-Roldán D, Rojo-Lazo F, CalzadillaNúñez A, San Martín-Roldán P, Díaz-Calzadilla $P$, Díaz-Narváez VP. Prediction of end of lockdown post-peak of cases in first wave of the COVID-19 pandemic in Chile. Medwave [revista en la Internet]. 30 de noviembre de 2020; 20(10): e8057-e8057. Disponible en: https://www.medwave.cl/link.cgi/Medwave/Revisi ones/Analisis/8057.act

55. Ministerio de Salud y Protección Social (Colombia). Resolución 1513 de 2020 [Internet]. 2020 [citado 8 de abril de 2021]. p. 11. Disponible en:
https://www.minsalud.gov.co/Normatividad_Nuev o/Resolución No. 1513 de 2020.pdf

56. Ministerio de Salud (Argentina). Cidados principales [Internet]. 2020 [citado 8 de abril de 2021]. p. $1 . \quad$ Disponible en: https://www.argentina.gob.ar/salud/coronavirus/p oblacion/prevencion

57. Gobierno de Chile. Plan de Acción implementado por el Gobierno de Chile para hacer frente a emergencia por Coronavirus [Internet]. 2020 [citado 8 de abril de 2021]. p. 1. Disponible en: https://chilereports.cl/noticias/2020/05/13/plande-accion-implementado-por-el-gobierno-de-chilepara-hacer-frente-a-emergencia-por-coronavirus

58. Ministerio de Salud Pública y Bienestar Social (Paraguay). Resolución 300 [Internet]. 2020 [citado 8 de abril de 2021]. p. 15. Disponible en: https://www.mspbs.gov.py/dependencias/portal/a djunto/d2bb92-

ResolucinN300Protocolodevigilanciaepidemiolgicay manejodeaislamientopreventivo.pdf

59. Gobierno de Bolivia. Guia para el Manejo del COVID-19. 2020. p. 175.

60. Sistema Único de Saúde (SUS). Saúde anuncia orientações para evitar a disseminação do coronavírus [Internet]. 2020 [citado 8 de abril de 2021]. p. 1. Disponible en: https://www.unasus.gov.br/noticia/saude-anunciaorientacoes-para-evitar-a-disseminacao-docoronavirus

61. Blackman A, Ibañez AM, Izquierdo A, Keefer P, Moreira $\mathrm{M}$, Schady $\mathrm{N}$, et al. La política pública frente al Covid-19: recomendaciones para América Latina y el Caribe [Internet]. Washington, EE. UU.: Banco Interamericano de Desarrollo; abril 2020. Disponible en: https://publications.iadb.org/es/la-politicapublica-frente-al-covid-19-recomendaciones-paraamerica-latina-y-el-caribe

62. Singh D, Joshi K, Samuel A, Patra J, Mahindroo N. Alcohol-based hand sanitisers as first line of defence against SARS-CoV-2: a review of biology, chemistry and formulations. Epidemiol Infect [revista en la Internet]. 29 de septiembre de 2020; 148: e229. 
Disponible

en:

https://www.cambridge.org/core/product/identifie r/S0950268820002319/type/journal_article

63. Wilches Visbal J, Castillo Pedraza M. Aproximación matemática del modelo epidemiológico SIR para la comprensión de las medidas de contención contra la COVID-19. Rev Esp Salud Publica [revista en la Internet]. 2020; 94: e1$11 . \quad$ Disponible en: https://www.mscbs.gob.es/biblioPublic/publicacio nes/recursos_propios/resp/revista_cdrom/VOL94/ C_ESPECIALES/RS94C_202009109.pdf

64. Nakada LYK, Urban RC. COVID-19 pandemic: environmental and social factors influencing the spread of SARS-CoV-2 in São Paulo, Brazil. Environ Sci Pollut Res [Internet]. 28 de septiembre de 2020. Disponible en: http://link.springer.com/10.1007/s11356-02010930-w

65. Matrajt L, Leung T. Evaluating the Effectiveness of Social Distancing Interventions to Delay or Flatten the Epidemic Curve of Coronavirus Disease. Emerg Infect Dis [revista en la Internet]. Agosto de 2020; 26(8): $\quad 1740-8 . \quad$ Disponible en: http://wwwnc.cdc.gov/eid/article/26/8/201093_article.htm

66. Yang S, Lee GWM, Chen C-M, Wu C-C, Yu K-P. The Size and Concentration of Droplets Generated by Coughing in Human Subjects. J Aerosol Med [revista en la Internet]. Diciembre de 2007; 20(4): 484-94. Disponible en: http://www.liebertpub.com/doi/10.1089/jam.2007 .0610

67. Montenegro-López D. Uso de tecnologías en el lugar de atención para el manejo de la pandemia por COVID-19 en Colombia. Rev Panam Salud Pública [revista en la Internet]. 14 de agosto de 2020; 44: 1. Disponible en:

https://iris.paho.org/handle/10665.2/52559

68. Zapata-Herrera AF, Moreno-Correa SM. El uso de la luz ultravioleta para controlar la transmisión del virus SARS-CoV-2 en medios hospitalarios. Salut Sci Spiritus. 2020; 6(1): 107-15. Disponible en: https://revistas.javerianacali.edu.co/index.php/sal utemscientiaspiritus/article/download/2343/2895

69. Bachmann L. IV Simposio de Fotobiofísica - UV e Vírus: UVC em ambientes cerrados [Internet]. Universidade de São Paulo. 2020 [citado 16 de marzo de 2021]. p. 1. Disponible en: https://youtu.be/gszFyqaDbal

70. Mackenzie D. Ultraviolet Light Fights New Virus. Engineering [revista en la Internet]. Agosto de 2020; 6(8): 851-3. Disponible en: https://linkinghub.elsevier.com/retrieve/pii/S2095 809920301673

71. Wilches J, Castillo Pedraza MC, Apaza Veliz DG. Procedimiento para el uso de pirómetros durante la pandemia por COVID-19. Arch Med. 2020; 21(1). Disponible en: https://pesquisa.bvsalud.org/portal/resource/pt/bi blio-1148465?src=similardocs

72. Whitelaw S, Mamas MA, Topol E, Van Spall HGC. Applications of digital technology in COVID-19 pandemic planning and response. Lancet Digit Heal [revista en la Internet]. Agosto de 2020; 2(8): e435$40 . \quad$ Disponible en: https://linkinghub.elsevier.com/retrieve/pii/S2589 750020301424

73. Leon Singh HJ, Couch D, Yap K. Mobile Health Apps That Help With COVID-19 Management: Scoping Review. JMIR Nurs. 2020; 3(1): e20596. Disponible en: https://nursing.jmir.org/2020/1/e20596/

74. Palazzi P, Rosa DS, Silva P, Sepúlveda J, Acosta J, López $\mathrm{M}$ del $\mathrm{P}$, et al. Algunas aplicaciones que están siendo utilizadas en América Latina para tratar de controlar la propagación del COVID-19 [Internet]. International Association of Privacy Professionals. 2020 [citado 15 de febrero de 2021]. p. 1. Disponible en: https://iapp.org/news/a/algunas-aplicacionesque-estan-siendo-utilizadas-en-america-latinapara-tratar-de-controlar-la-propagacion-del-covid19/ 